ANNUAL PROGRESS REPORT: 2005-2006

\title{
Project (DE-FG-02-06ER64190) Title: Coupling Sorption to Soil Weathering During Reactive Transport: Impacts of Mineral Transformation and Sorbate Aging on Contaminant Speciation and Mobility
}

Lead Principal Investigator: Dr. Jon Chorover, Department of Soil, Water and Environmental Science, 429 Shantz Building, University of Arizona, AZ 85721: Tel: (520) 626-5635; Email: chorover@cals.arizona.edu

Co-Investigators: Dr. Karl T. Mueller, Department of Chemistry, 152 Davey Laboratory, The Pennsylvania State University, University Park, PA 16802; Tel: (814) 863-8674; Email: ktm2@ psu.edu; Dr. Peggy O’Day, School of Natural Sciences, University of California, Merced, CA 95344; Tel: (209) 724-4338; Fax: (209) 724-2912; E-mail: poday@ucmerced.edu; Mr. R. Jeff Serne, Pacific Northwest National Laboratory, Applied Geology \& Geochemistry Group, Richland, WA 99352; Tel: (509) 376-8429; Email: jeff.serne@ pnl.gov ; Dr. Wooyong Um, Pacific Northwest National Laboratory, Applied Geology \& Geochemistry Group, Richland, WA 99352; Tel: (509) 376-4627; Email: wooyon.um@pnl.gov; Dr. Carl Steefel, Lawrence Berkeley National Laboratory, CA 94720; Tel: (510) 486-7311; Email: CISteefel@lbl.gov. Graduate Students: Garry Crosson, Geoffrey Bowers, Nelson Rivera, Jason Field. Postdoctoral Scholar: Sunkyung Choi, Aaron Thompson.

\section{Introduction.}

Our work is aimed at developing a predictive-mechanistic understanding of the coupling between mineral weathering from caustic waste release and contaminant (Cs, Sr, I) fate and transport in waste-impacted sediments across space, time and geochemical gradients that encompass the process-level heterogeneity observed at the Hanford DOE site. Our specific objectives are: (1) to assess the molecular-scale mechanisms responsible for time-dependent sequestration of contaminants ( $\mathrm{Cs}$, $\mathrm{Sr}$ and I) during penetration of waste-induced weathering fronts through sedimentary media; (2) to determine the rate and extent of contaminant release from the sorbed state; (3) to develop a reactive transport model based on molecular mechanisms and macroscopic flow experiments (from (1) and (2)) that accurately simulates adsorption, aging, and desorption at the bench-scale, and that can be applied to - and validated at - field sites such as Hanford.

\section{Summary of Results.}

Laboratory experiments and reactive transport modeling aimed at coupling knowledge of fundamental molecular mechanisms with bench-scale transport experiments to develop generalized transport model parameters. Studies of the reactivity of radionuclides (Cs and Sr) in STWL with Hanford sediments [Hanford coarse sand [HC], Hanford fine sand [HF], and Ringold silt [RG]) were conducted by coupling macroscopic sorption-desorption experiments with spectroscopic and microscopic investigations over a wide range of reaction times. Solutions were analyzed by inductively coupled plasma-mass spectrometry (ICP-MS). Solid products (referred to here as "secondary phases" relative to the initial reactant minerals) were analyzed for time-dependent changes in mineralogy and modes of contaminant bonding by a variety of methods, including X-ray diffraction (XRD), scanning and transmission electron microscopy (SEM and TEM) with energy dispersive spectrometry (EDS), thermo gravimetric analysis (TGA), nuclear magnetic resonance (NMR), X-ray absorption spectroscopy (XAS), including extended X-ray absorption fine structure (EXAFS) and X-ray absorption near-edge structure (XANES) analysis, and Fourier-transform infrared spectroscopy (FTIR). Transport experiments at different bench scales (saturated and unsaturated conditions) were used and both batch and flow-through results were integrated with reactive transport models.

\section{Sr \& Cs uptake and extractions}

$\mathrm{Sr}$ and Cs uptake/extractions as a function of time (Figure 1 and 2) show different uptake between $\mathrm{Sr}$ and $\mathrm{Cs}$ and among Hanford sediments as well. Sr shows higher uptake than Cs, and $\mathrm{Sr}$ is less reversible in strong extractions than $\mathrm{Cs}$, consistent with increasing recalcitrance with aging. 

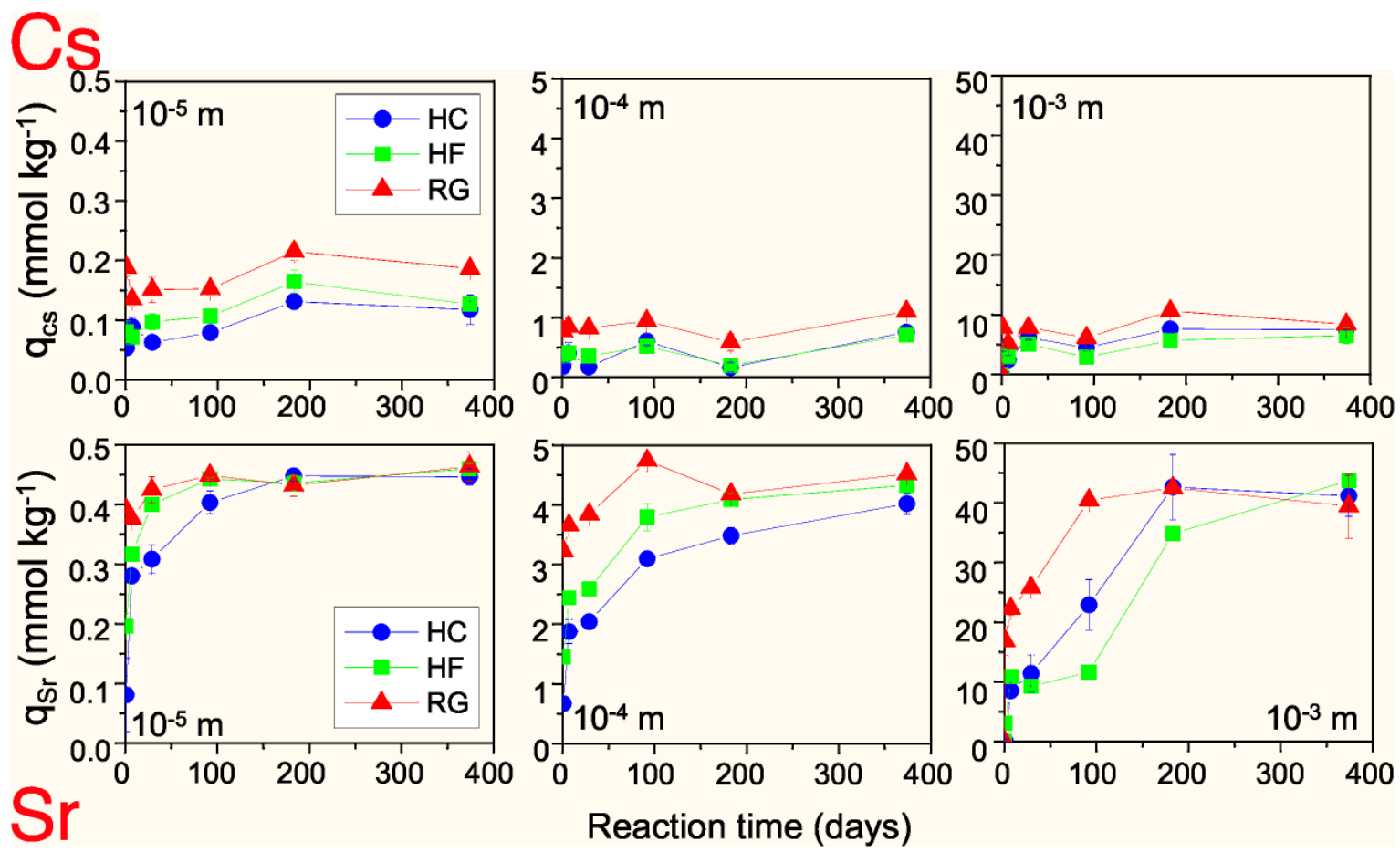

Figure 1. Sr and Cs uptake with Hanford Sediments as a function of time.

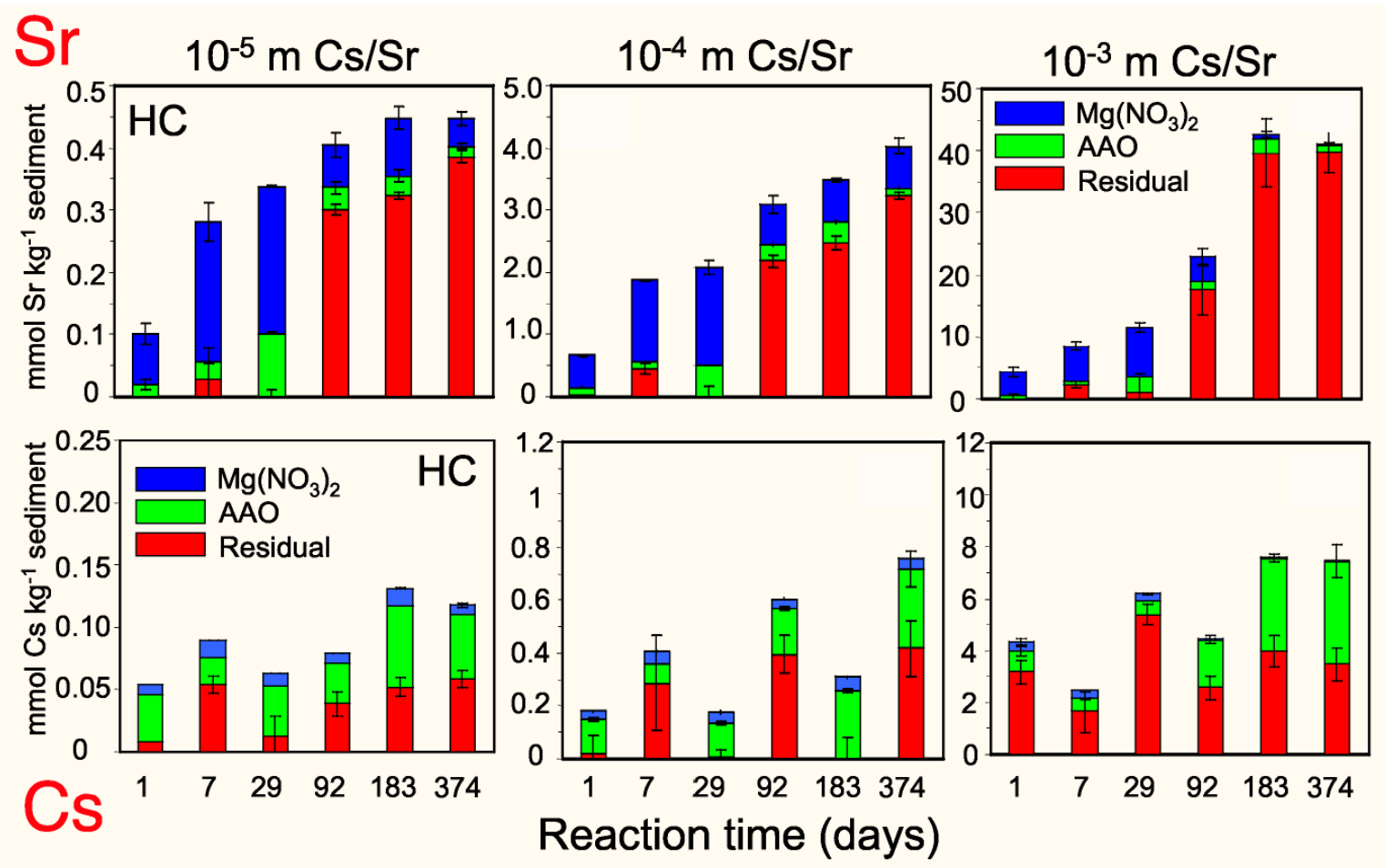

Figure 2. Sr and Cs extractions as a function of time. 
The SEM images show visual differences in reaction products between Hanford Coarse and Ringold Silt importance of clay mineral amount and type in determining reaction products (Figure 3). Rate of formation of secondary aluminosilicate is limited by Si supply from dissolution of primary minerals.

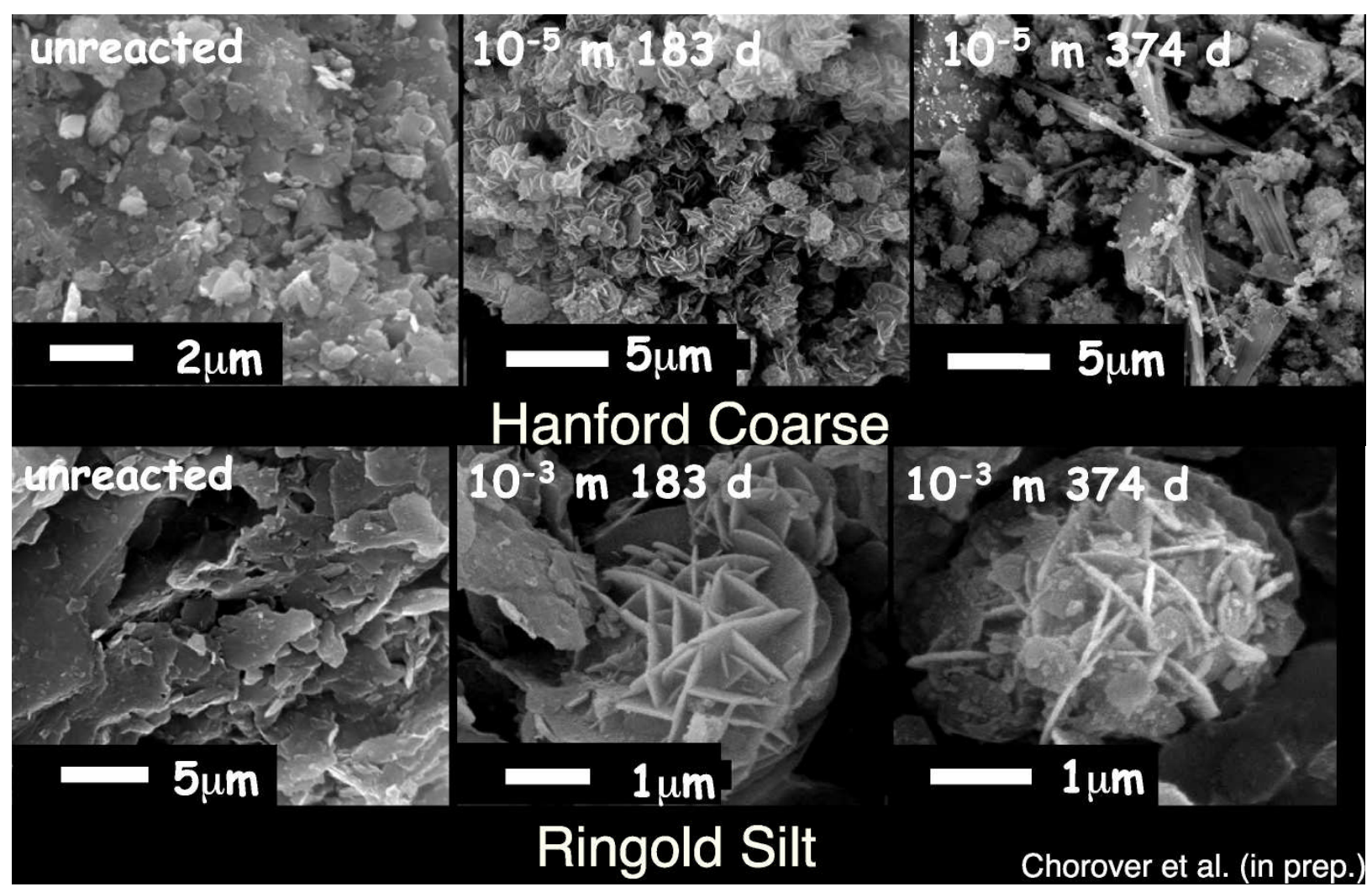

Figure 3. SEM images of unreacted and reacted sediments

\section{Solid-State NMR}

Kinetics from NMR: Our previous study of model clay systems provides an essential baseline for interpretation of the more complex sediments. Using MAS NMR at three different magnetic fields, our groups have collaborated on an in-depth study of the kinetics of kaolinite dissolution and neophase formation during weathering by our STWL solutions. At higher fields, the quadrupolar interaction experienced by the $\mathrm{Al}$ spins moves and narrows the lines, and we identify four different neo-phase resonances in the tetrahedral region of the $\mathrm{Al}$ spectrum (Figure 4). These spectra are quantitative, and we show here the growth of sodalite and cancrinite phases, as well as the trade off between this speciation, as a function of reaction time for three different $\mathrm{Cs}$ and $\mathrm{Sr}$ concentrations in the STWL.

\section{Synchrotron $X R F / X R D$}

Synchrotron micro-XRF (ALS) provided the elemental map for Sr. After eliminating most reflections from detrital minerals, $\mu$-XRD collected on hot spots showed unequivocally the presence of sodalite and cancrinite secondary phases in Hanford Coarse sediment after 1 year of reaction (Figure 5). 

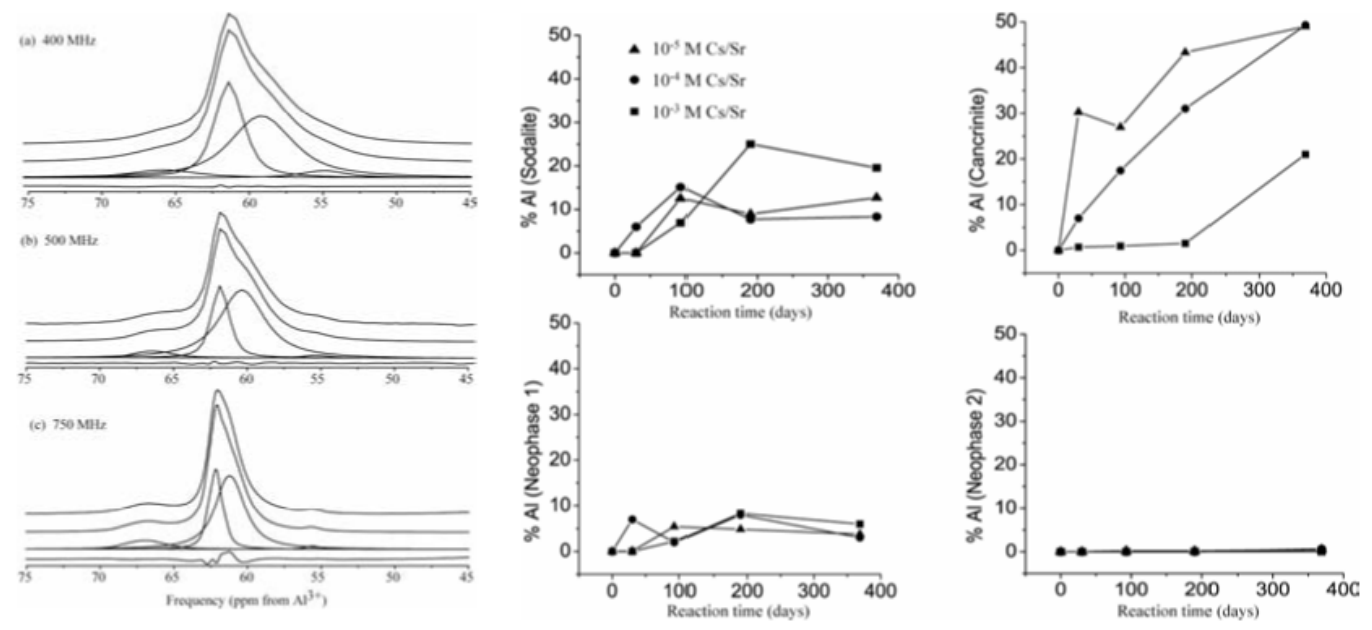

Figure 4. ${ }^{27} \mathrm{Al}$ MAS NMR acquired at three magnetic field strengths (left: top- $400 \mathrm{MHz}$, middle-500 Mhz, bottom-750 MHz) provide the data for full quantification of secondary solid phase speciation for specimen kaolinite samples reacted with a STWL solution throughout the time series and as a function of Sr and Cs co-contaminant concentrations (adapted from Crosson, 2005).
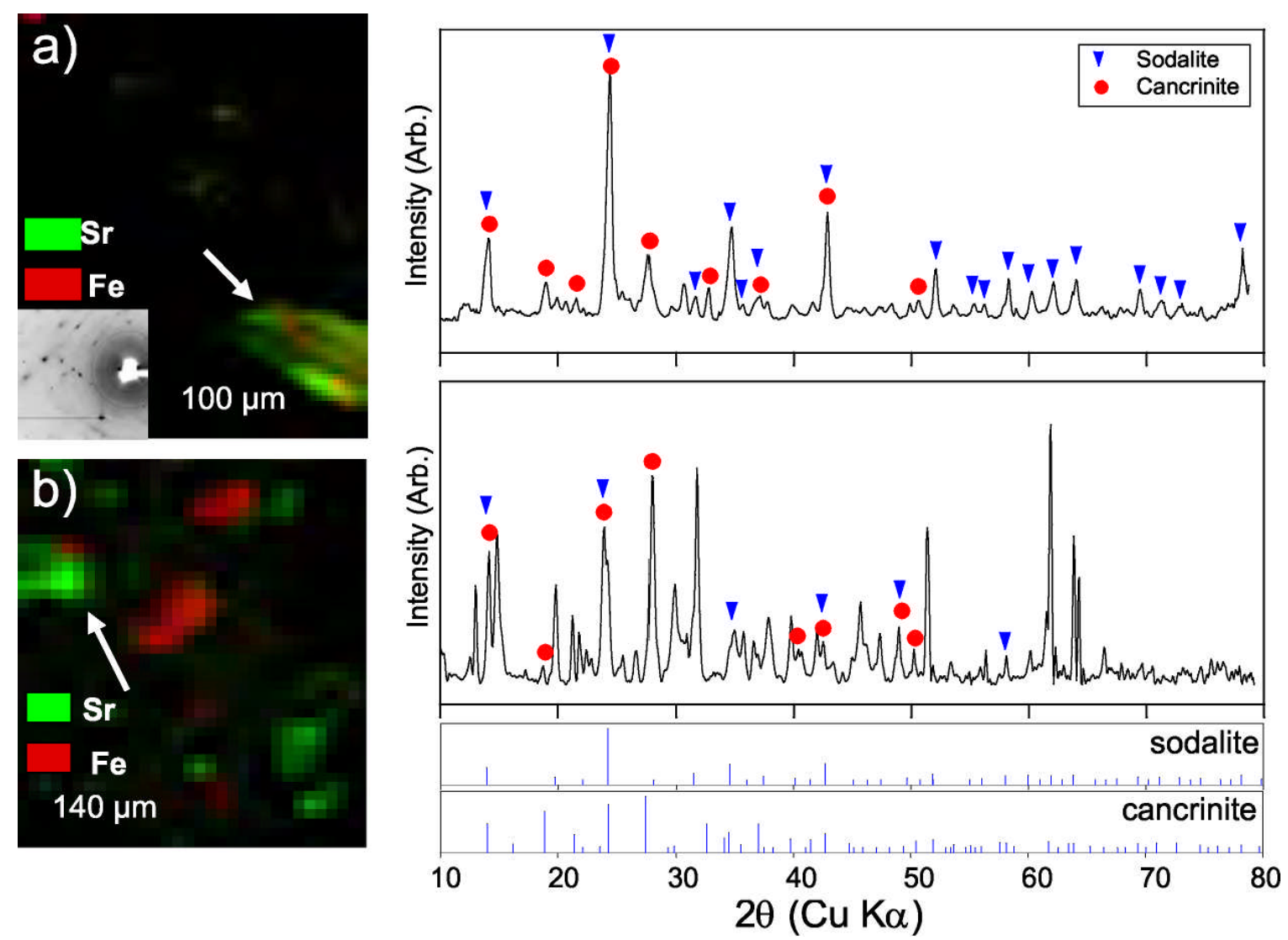

Figure 5. Synchrotron micro-XRF and XRD showed Sr map and secondary precipitates in 1 year reacted sediments. 


\section{Synchrotron XAS}

Bulk and micro-EXAFS of $\mathrm{Sr}$ on kaolinite as a probe of the molecular coordination around Sr provides complementary information to NMR. Bulk spectrum at $30 \mathrm{~d}$ aged shows little near-neighbor backscattering (Figure 6). Three different microfocused EXAFS show different features interpreted as hydrated and dehydrated $\mathrm{Sr}$ in neoformed feldspathoids. Bulk time series shows presence of $\mathrm{SrCO}_{3}$ at 1 and $7 \mathrm{~d}$ that is replaced with time. Backscattering peak from $\mathrm{Al} / \mathrm{Si}$ increases as aging time, indicating of increasing importance of secondary aluminosilicate phases as reaction time increases.

Micro-EXAFS: neoformed particles 33d
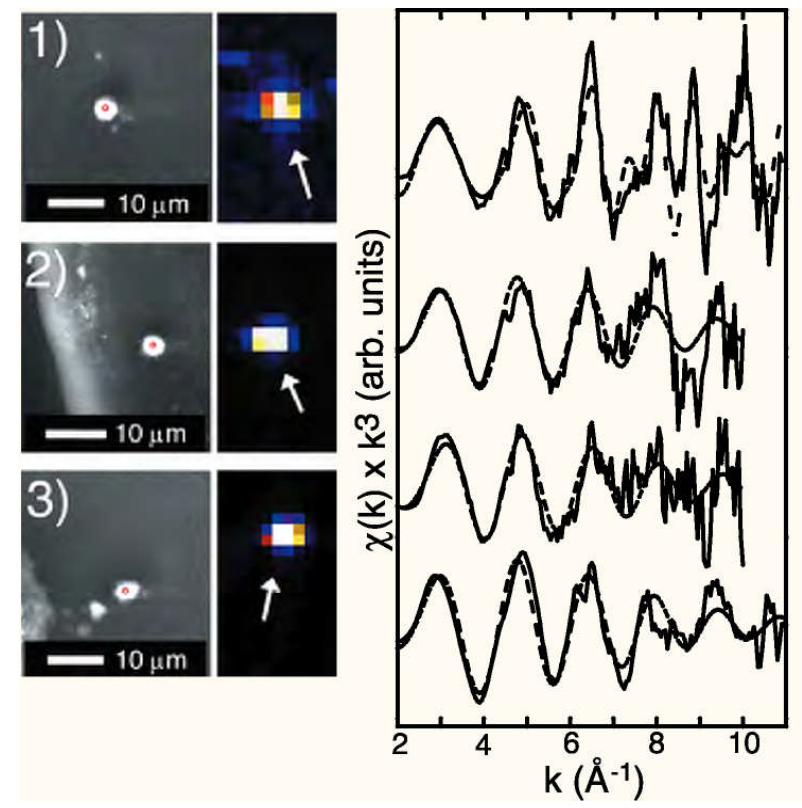

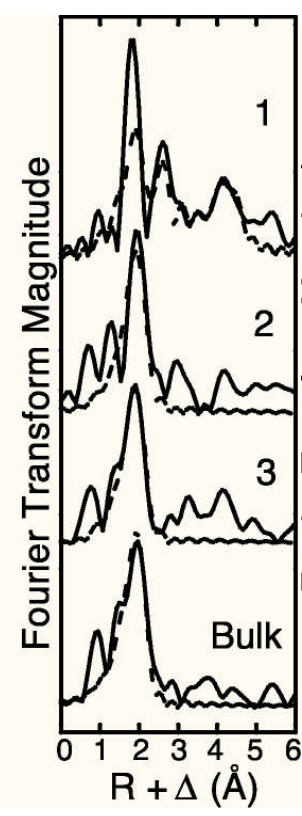

Bulk EXAFS

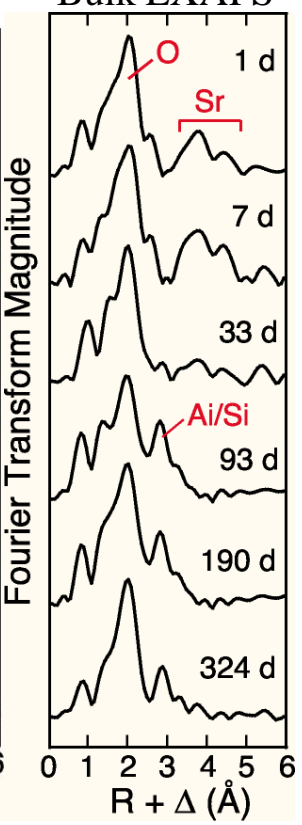

Figure 6. Micro and bulk Sr EXAFS on neoformed particles after 33 day reaction.

Bulk EXAFS data for model clays (2:1 and 1:1) after aging 1 year show very apparent spectral features for $\mathrm{SrCO}_{3}$ (Figure 7). $\mathrm{No} \mathrm{SrCO}_{3}$ is found in kaolinite. Illite, with the smallest amount of dissolution, has all $\mathrm{SrCO}_{3}$ or sorbed Sr. Montmorillonite and vermiculite show mixtures of $\mathrm{SrCO}_{3}$ and feldspathoid phases (consistent with XRD and FTIR results not shown). Bulk EXAFS data for Hanford Coarse and Ringold sediments after 1 year reaction and AAO extraction are shown in Figure 8. Presence of $\mathrm{SrCO}_{3}$ in $\mathrm{HC}$ that is removed by the AAO extraction, leaves recalcitrant secondary aluminosilicates. Bulk data shown previously indicates that most $\mathrm{Sr}$ is associated with the recalcitrant phase. The EXAFS for AAO does not show extensive second-neighbor backscattering, probably because of overlap from $\mathrm{Sr}$ in different atomic sites. Ringold shows no carbonate and less difference between unextracted and extracted, although some less crystalline phases are removed with AAO. Comparison points out the variability in products and presence or absence of $\mathrm{SrCO}_{3}$ - readily precipitated if solubility exceeded, and readily dissolved (no kinetic barriers). 

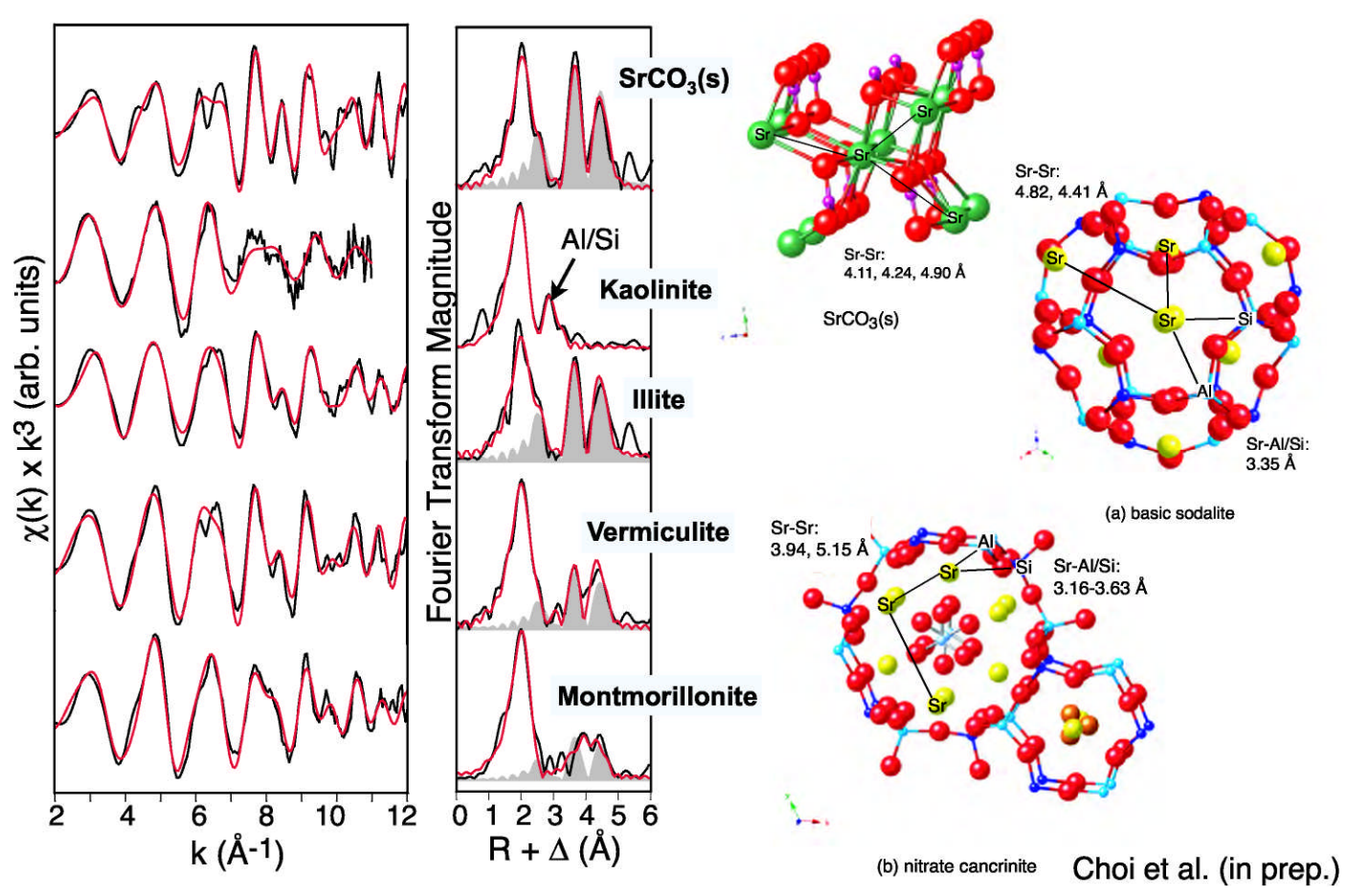

Figure 7. Bulk Sr EXAFS for model clays after 1 year reaction.
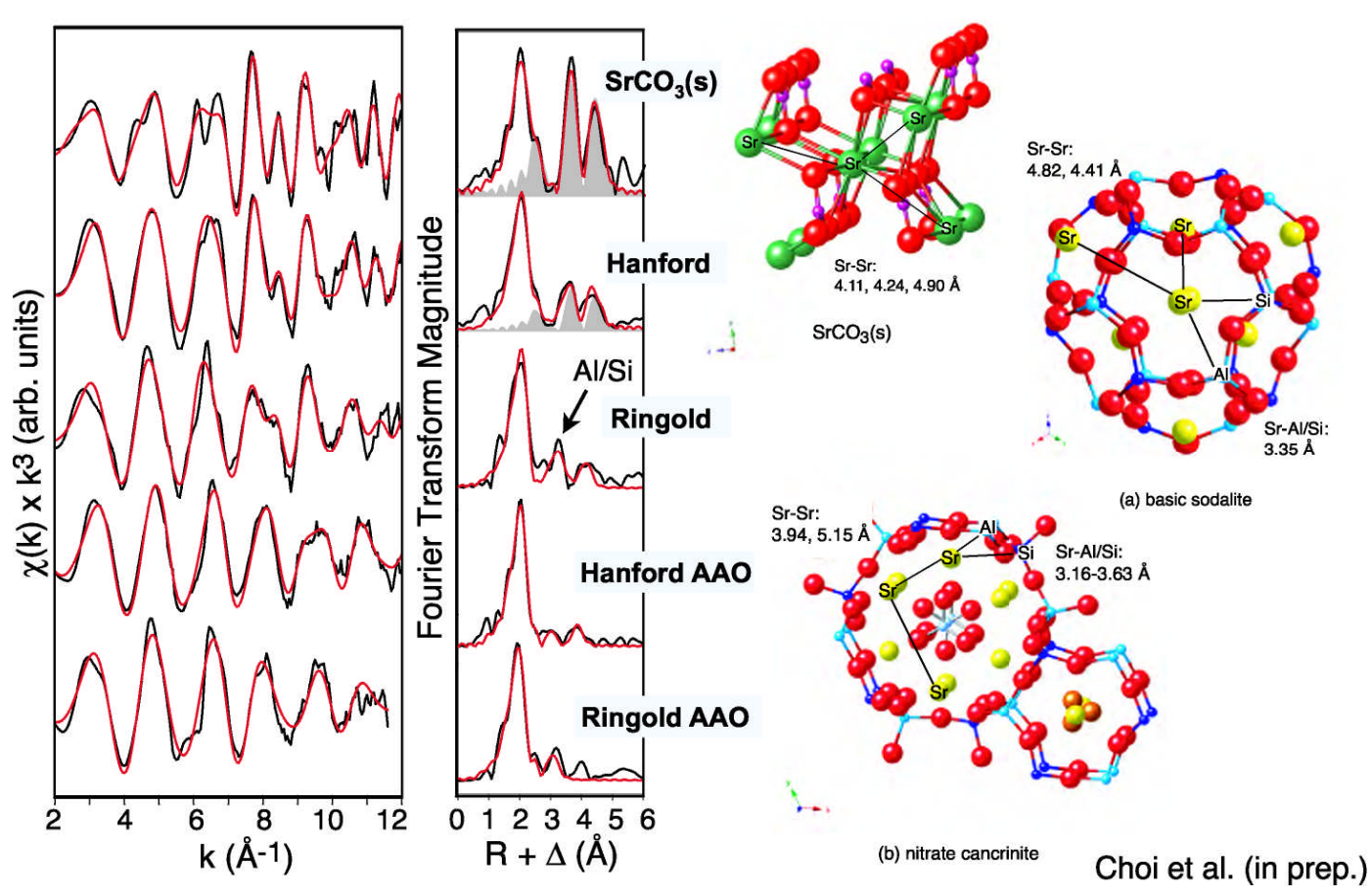

Figure 8. Bulk Sr EXAFS for Hanford sediment after 1 year reaction and AAO extracted. 


\section{Desorption and Transport Modeling}

Preliminary desorption studies with aged sediment using a batch fill-refill method indicates much higher retention of Cs than the 3-site model predicts. This may be due to sequestration of Cs by neoformed minerals (e.g., Cancrinite or Sodalite). When data from Mon et al (2005) is used to develop a similar model assuming Cs sorption occurs solely on those minerals, the Sodalite model matches the experimental data quite well (Figure 9). Sodalite was found in the reacted sediments and may be involved in the retention of Cs.

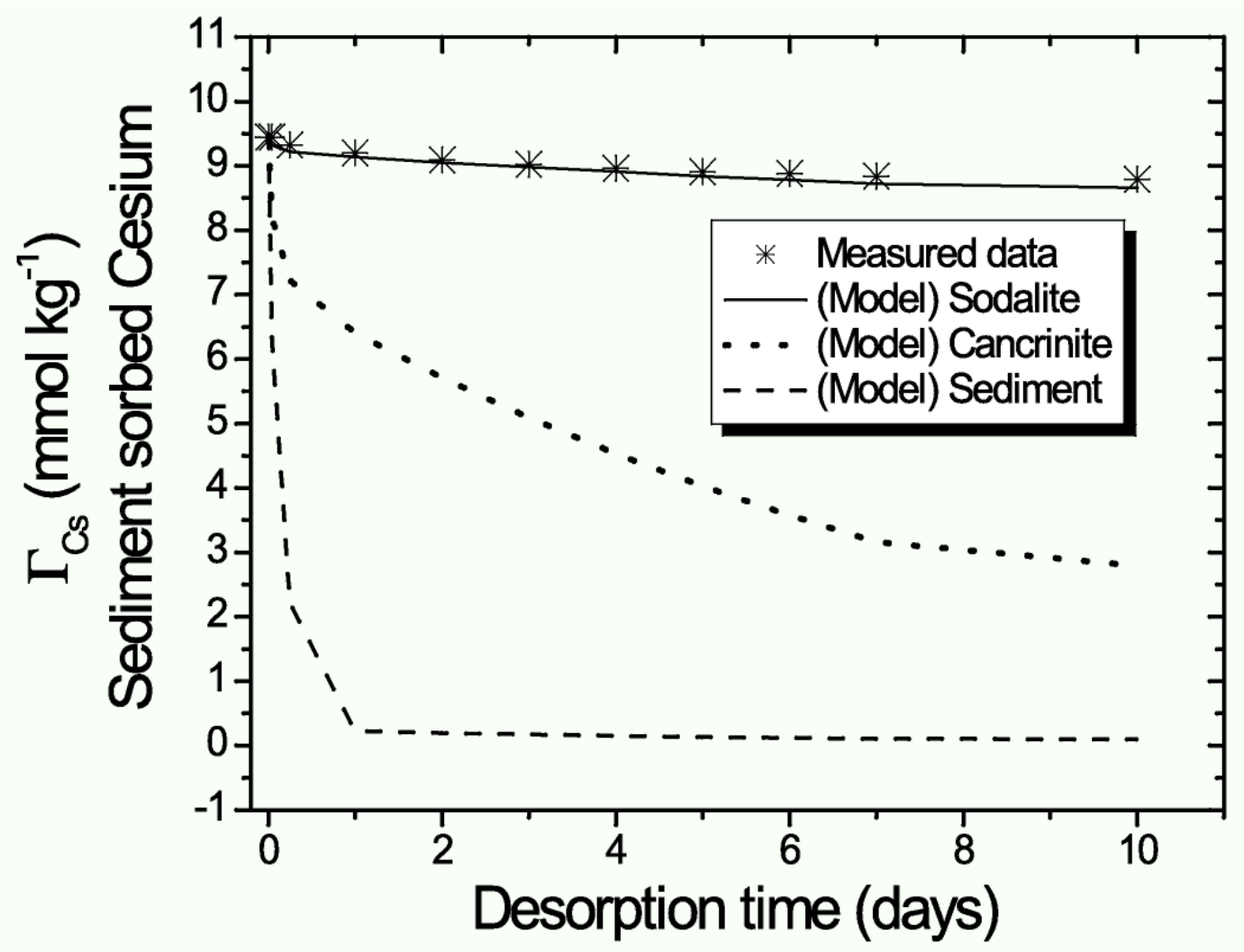

Figure 9. Preliminary desorption experiment after aging 10 months and transport modeling

\section{Unsaturated Column Studies}

For unsaturated column setup, an acrylic column with internal diameter $(3.81 \mathrm{~cm})$ and length $(20.3 \mathrm{~cm})$ was used in a hanging water column system. Pure quartz sand (50-70 mesh; Aldrich, Milwaukee, WI) was used for packing the column. Porous ceramic tensiometers, made of $1.37 \mathrm{~cm}$ OD plastic pipe with a $0.67 \mathrm{~cm}$ OD ceramic porous cup $(2.54 \mathrm{~cm}$ long $)$ at the lower end and a $6 \mathrm{~cm}$ section of clear plastic pipe at the upper end (Soil Measurement Systems, Tucson, AZ) are used to monitor water potential. Two tensiometers were mounted on opposite sides of each column at $5 \mathrm{~cm}$ from each column ends thus yielding a $10 \mathrm{~cm}$ length between the two tensiometers. Each tensiometer was connected to a model 130 pressure transducer, with a pressure range up to 1 bar and operating temperature range of -30 to $70^{\circ} \mathrm{C}$ [purchased through Soil Measurement Systems(SMS)], which are connected to a datalogger (CR1000, Campbell Scientific Inc., CA) to monitor water potential. Care was taken to ensure a continuous column of water between the saturated porous cup and the transducer. A low-flow peristaltic pump (Fisherbrand* Variable-Flow Peristaltic Pump, Fisher Scientific) was used to introduce solution to the packed quartz column inlet (top of the column), which is covered by nylon membrane. Although a sprinkler was not used to introduce the solution, the influent drops naturally could disperse and spread out on the nylon membrane prior to percolating into the packed quartz column. Several venting ports were placed near the inlet surface to allow air exchange freely. A constant water potential (suction) was controlled by a hanging water column attached to the outlet at the bottom of the column. The weight of the column was 
measured using a balance to monitor the water content change before and after the experiment. Although no continuous monitoring of the weight of the column throughout the experiments is acquired, water content variance can be indirectly measured by continuous water potential records in the datalogger from the two tensiometers installed in the column during the experiments. The experimental setup for performing unsaturated column experiments and column apparatus are shown in Figure 10.

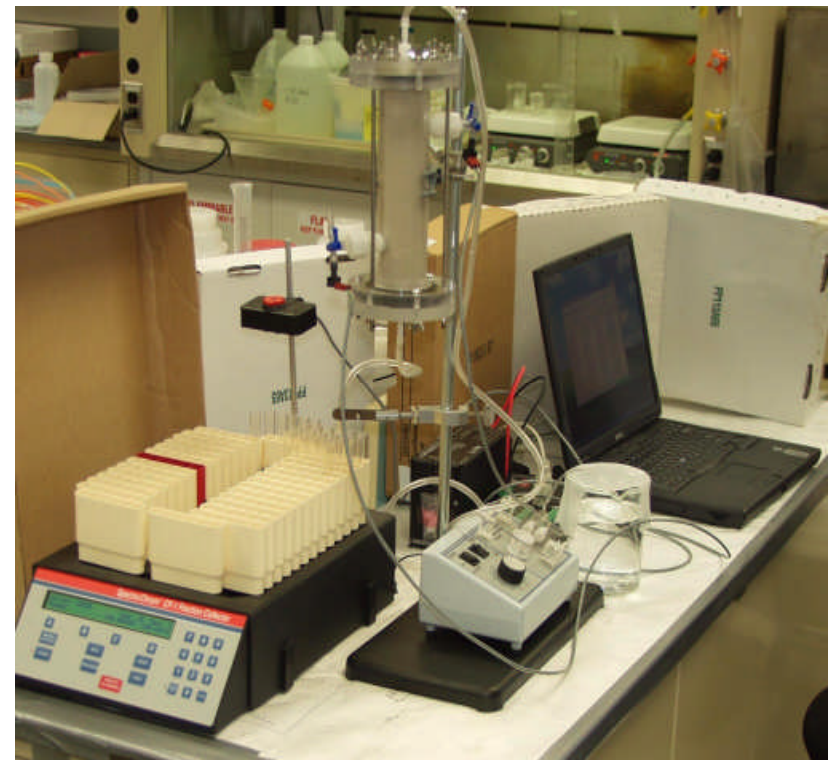

(a)

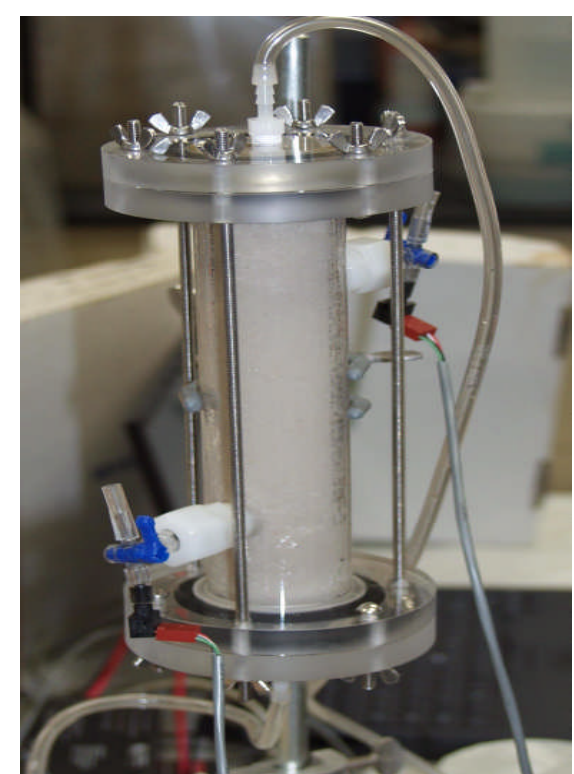

(b)

Figure 10. Experimental set up for transport experiments in unsaturated column (a) and quartz sand packed column (b)

Hydraulic properties were measured during this initial stage. A soil-water retention curve was developed using desaturation and resaturation procedures (Figure 11). Hysteresis is generally always found between these two procedures and our results did show such. The desaturated water retention curve was analyzed using the parametric model of van Genuchten,

$$
S_{e}=\frac{\theta_{v}-\theta_{r}}{\theta_{s}-\theta_{r}}=\left[1+(\alpha h)^{n}\right]^{\left(-1+\frac{1}{n}\right)}
$$

where $S_{e}$ is the effective saturation, $\theta_{v}$ is the volumetric water content, $\theta_{r}$ is the residual water content, $\theta_{s}$ is the saturated water content, $\alpha$ is the inverse of the air-entry potential, $h$ is the water potential, $n$ is the parameter related to the pore size distribution (from the slope of the steepest part of the curve with the steeper $=$ narrow pore size distribution). The measured data (water contents vs. suction pressure) were fit by a curve fitting program using a RETC code (Van Genuchten et al. 1991). Based on the water retention curve, three columns are being run at 3 different effective saturation levels $(0.24,0.37,0.82 \%)$ representing $-40,-30$, and $-20 \mathrm{~cm}$ suction, respectively. The $\mathrm{R}^{2}$ is regression coefficient for curve fit. The STWL including Sr, Cs, and I was introduced into columns and data are still being collected. 


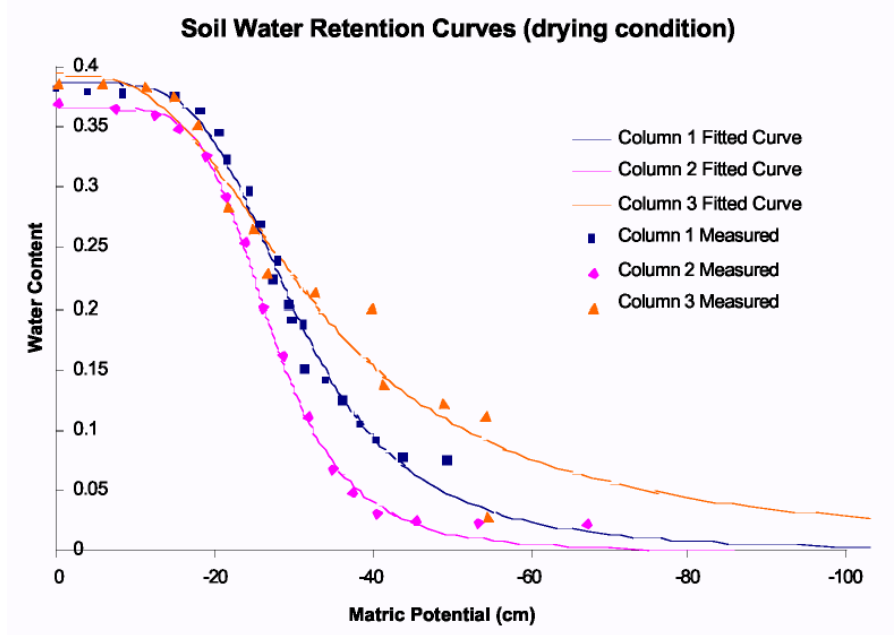

\section{Curve Fit Results (RETC)}

$\begin{array}{llll}\text { Column \# } & 1 & 2 & 3 \\ \text { Saturation } & 24 \% & 37 \% & 82 \% \\ \text { (Suction) } & (-40 \mathrm{~cm}) & (-30 \mathrm{~cm}) & (-20 \mathrm{~cm}) \\ \mathrm{R}^{2} & 0.978 & 0.997 & 0.954 \\ \Theta_{\mathrm{s}} & 0.388 & 0.367 & 0.394 \\ \alpha & 0.035 & 0.038 & 0.036 \\ \mathrm{n} & 4.68 & 6.00 & 3.04\end{array}$

Figure 11. Water retention curve for quartz sand and model fit for the drying curve from saturation by van Genuchten equation.

\section{Works in Progress and for Future.}

1. Contaminant desorption studies will be conducted through flow-through column experiments at different saturation scales using the reacted sediments in batch reactors (with and without $\mathrm{CO}_{2}$ environment). Desorption rates will be measured with different flush solutions to simulate field scenarios.

2. Unsaturated column experiments for the STWL including Sr, Cs, and I are still under way. Desorption of reacted sediments will be also conducted in unsaturated condition.

3. New applications of NMR for the study of $\mathrm{Sr}$ sequestered in a designer fluoromica will be conducted. In other work, which we are now transferring to our studies of clays and Hanford sediments, the Mueller group has been attaching reactive fluorinated-chlorosilane molecules to low-surface area oxides, including clays, and monitoring changes in reactive surface area via a highly sensitive F-19 MAS experiment. Rather than providing a non-chemically meaningful measure of surface area, this measurement quantifies the number of reactive surface hydroxyl groups, an important chemical property of the surface.

4. Development of tomographic imaging at different scales will be conducted for quantification of porosity and pore connectivity; heterogeneity at different scales. This will be used to help link physical and chemical properties for reactive transport models.

5. Molecular and laboratory columns scaled results will be used to improve transport model and to predict contaminant desorption from reacted sediments.

\section{References}

Van Genuchten, M. T. 1980. A closed-form equation for predicting the hydraulic conductivity of unsaturated soils, Soil Sci. Soc. Am. 1980, 44, 892-898.

Crosson, G. 2005. Quantitative and qualitative solid-state Nuclear Magnetic Resonance studies of hydroxide promoted dissolution of layered silicates. Department of Chemistry (Mueller-Major Advisor). Penn State University. Ph.D. Thesis. 